\title{
Microscale wear behavior and crosslinking of PEG-like coatings for total hip replacements
}

\author{
Sheryl R. Kane $\cdot$ Paul D. Ashby $\cdot$ Lisa A. Pruitt
}

Received: 12 September 2009/ Accepted: 4 November 2009/Published online: 20 December 2009

(c) The Author(s) 2009. This article is published with open access at Springerlink.com

\begin{abstract}
The predominant cause of late-state failure of total hip replacements is wear-mediated osteolysis caused by wear particles that originate from the ultrahigh molecular weight polyethylene (UHMWPE) acetabular cup surface. One strategy for reducing wear particle formation from UHMWPE is to modify the surface with a hydrophilic coating to increase lubrication from synovial fluid. This study focuses on the wear behavior of hydrophilic coatings similar to poly(ethylene glycol) (PEG). The coatings were produced by plasma-polymerizing tetraglyme on UHMWPE in a chamber heated to $40^{\circ} \mathrm{C}$ or $50^{\circ} \mathrm{C}$. Both temperatures yielded coatings with PEG-like chemistry and increased hydrophilicity relative to uncoated UHMWPE; however, the $40^{\circ} \mathrm{C}$ coatings were significantly more resistant to damage induced by atomic force microscopy nanoscratching. The $40^{\circ} \mathrm{C}$ coatings exhibited only one damage mode (delamination) and often showed no signs of damage after repeated scratching. In contrast, the $50^{\circ} \mathrm{C}$ coatings exhibited three damage modes (roughening, thinning, and delamination), and always showed visible signs of damage after no more than two scratches. The greater wear resistance of the $40^{\circ} \mathrm{C}$ coatings could not be explained by coating chemistry or hydrophilicity, but it corresponded to an approximately
\end{abstract}

S. R. Kane $\cdot$ L. A. Pruitt $(\square)$

Joint Graduate Group in Bioengineering, U.C. San Francisco and U.C. Berkeley, 5134 Etcheverry Hall, MC 1740,

Berkeley, CA 94720, USA

e-mail: 1pruitt@me.berkeley.edu

P. D. Ashby

Molecular Foundry, Lawrence Berkeley National Laboratory, Berkeley, CA 94720, USA

L. A. Pruitt

Mechanical Engineering, U.C. Berkeley, Berkeley,

CA 94720, USA
26-32\% greater degree of crosslinking relative to the $50^{\circ} \mathrm{C}$ surfaces, suggesting that crosslinking should be a significant design consideration for hydrophilic coatings used for total hip replacements and other wear-dependent applications.

\section{Introduction}

The long-term success of total hip replacements (THRs) depends on a number of factors, including implant design, surgical skill, and infection rates. However, the most common cause of late-stage THR failure is wear-mediated osteolysis, an immune response to wear particles from the articulating surfaces that results in pain, bone loss, and implant loosening [1, 2]. The predominant strategy to improve THR longevity is to reduce wear particle formation.

In the United States, ultrahigh molecular weight polyethylene (UHMWPE) is the most common material used for acetabular cups [2]; it is also the predominant source of wear particles in metal-on-UHMWPE and ceramic-onUHMWPE implants [1-3]. In the past decade, much effort has focused on the use of irradiation schemes to provide bulk crosslinking in order to improve the wear behavior of UHMWPE [4, 5]; however, this approach renders the polymer susceptible to decreased fracture resistance $[6,7]$. An alternative solution to decrease wear particle formation from UHMWPE is to modify only the surface, rather than the bulk, and one approach is to coat the surface with a lubricious hydrogel [8-10].

We have developed a coating made of plasma-polymerized tetraglyme, an oligomer similar to poly(ethylene glycol) (PEG) [11]. Unlike other hydrogel coatings that have been examined to date, this coating is both crosslinked and covalently bonded to the UHMWPE surface. Covalent attachment to the UHMWPE surface should 
minimize coating loss during articulation. Crosslinking should increase the structural integrity of the coatings, enabling them to resist wear-induced surface damage. For this reason, care was taken to assess the relative crosslink density of the coatings.

This study utilized a number of surface characterization methods, including X-ray photoelectron spectroscopy (XPS), infrared spectroscopy, contact angle measurement, and crosslink density assessment, along with atomic force microscopy (AFM) wear testing, in order to evaluate the micron-scale wear behavior of PEG-like coatings on UHMWPE. AFM nanoscratching, which allows for both imaging and quantification of surface damage, was chosen to simulate asperity wear and identify the predominant wear behavior(s) of the coatings. This work elucidates the relationship between observed wear modes and crosslinking at the bearing surface and facilitates a pathway for developing wearresistant surface treatments for UHMWPE used in THRs.

\section{Materials and methods}

\subsection{Materials}

UHMWPE substrates for XPS, infrared spectroscopy, and contact angle goniometry were cut from $250 \mu \mathrm{m}$ thick sheets, while AFM substrates were cut from rod stock UHMWPE (both McMaster-Carr). The AFM samples were microtomed using a Reichert Ultracut $\mathrm{E}$ with a fresh glass blade. All substrates were cleaned by successive sonication in $1 \%$ Aquet solution (Bel-Art Products), deionized water $3 \mathrm{x}$, acetone, and isopropanol (Sigma-Aldrich).

\subsection{Plasma deposition}

Clean UHMWPE substrates were coated with tetraglyme (Sigma-Aldrich) using a Plasma Science PS0500 parallelplate reactor with a $13.56 \mathrm{MHz}, 550$ watt $\mathrm{RF}$ generator. The chamber was heated to $40^{\circ} \mathrm{C}$ or $50^{\circ} \mathrm{C}$ during the entire deposition process. A high-power argon treatment $(400 \mathrm{~W}$, $250 \mathrm{sccm}, 3 \mathrm{~min}$ ) was used to activate the UHMWPE surface to promote covalent attachment of the coating. Then tetraglyme was plasma polymerized onto the surface at $50 \mathrm{~W}, 30 \mathrm{sccm}$ argon, with $6 \mathrm{ml} / \mathrm{h}$ tetraglyme flow through a $130^{\circ} \mathrm{C}$ heated tube, for $2-30 \mathrm{~min}\left(40^{\circ} \mathrm{C}\right.$ chamber $)$ or $20-40 \mathrm{~min}\left(50^{\circ} \mathrm{C}\right.$ chamber), producing a range of coating thicknesses.

\subsection{X-ray photoelectron spectroscopy (XPS)}

XPS was performed on a Surface Science Instruments $\mathrm{S}$-probe spectrometer with a monochromatized Al source at a $55^{\circ}$ take-off angle. For each plasma deposition batch, survey and high-resolution $\mathrm{C}$ 1s spectra were collected at two spots on two samples. High-resolution C 1s spectra were peak fit with the Service Physics ESCAVB Graphics Viewer to resolve the hydrocarbon, ether, and carbonyl peaks.

\subsection{Contact angle goniometry}

The relative hydrophilicity of the surfaces was measured using a custom-made contact angle goniometer with a variable-magnification InfiniVar video microscope (Infinity Photo-Optical Co.), a 1.45 megapixel Sony XCD-SX910 camera, and LabView 7.1 software. $5 \mu \mathrm{l}$ of deionized water were pipetted onto the surface, and the drop was imaged in LabView and fit to a sphere. Two spots on two samples per plasma deposition batch were tested.

\subsection{Attenuated total reflection-Fourier transform infrared spectroscopy (ATR-FTIR)}

ATR-FTIR spectra were collected using a Nicolet Avatar 360 with an Omni-Sampler ATR accessory (Ge crystal, single-bounce beam path, $45^{\circ}$ incident angle, 32 scans, $4 \mathrm{~cm}^{-1}$ resolution). An advanced ATR correction was applied to all spectra and the region from 1800 to $900 \mathrm{~cm}^{-1}$ was peak fit using Omnic 7.3 software. The area under the most prominent ether peak at $\sim 1115 \mathrm{~cm}^{-1}$ was used to compare the relative thickness of different coatings. This method is discussed in more detail elsewhere [12].

\subsection{Atomic force microscopy scratch testing}

AFM nanoscratching was used to evaluate the microscale wear behavior of the coatings. Atomic force microscopy was performed with an Asylum Research MFP-3D using silicon cantilevers (Nanosensors FM tips, spring constant $2 \mathrm{nN} / \mathrm{nm}$ ) in phosphate buffered saline (PBS, Gibco) at $\mathrm{pH}$ 7.3. The surface was sequentially imaged non-destructively in tapping mode; sometimes lithographed in contact mode to produce a defect (ten passes along the lithography path, normal force 1-2 $\mu \mathrm{N})$; and scratched in contact mode (1$2.5 \mu \mathrm{N}$ ) to form a $4 \mu \mathrm{m}^{2}$ wear box. The surface was reimaged after lithography (which was omitted from some sequences to evaluate the behavior of fully intact coatings) and again after every 1-4 scratches. During scratching, the AFM also recorded images, which show the real-time scratching behavior of the coatings. Figure 1 is a schematic of the nanoscratching protocol.

Image analysis was performed using MFP-3D software and Igor Pro 6.02A. The first image taken served as a reference for all tapping-mode images. After scratching and re-imaging, the reference image was subtracted from each subsequent image to highlight wear-induced damage. In all tapping-mode images, the smooth region surrounding 


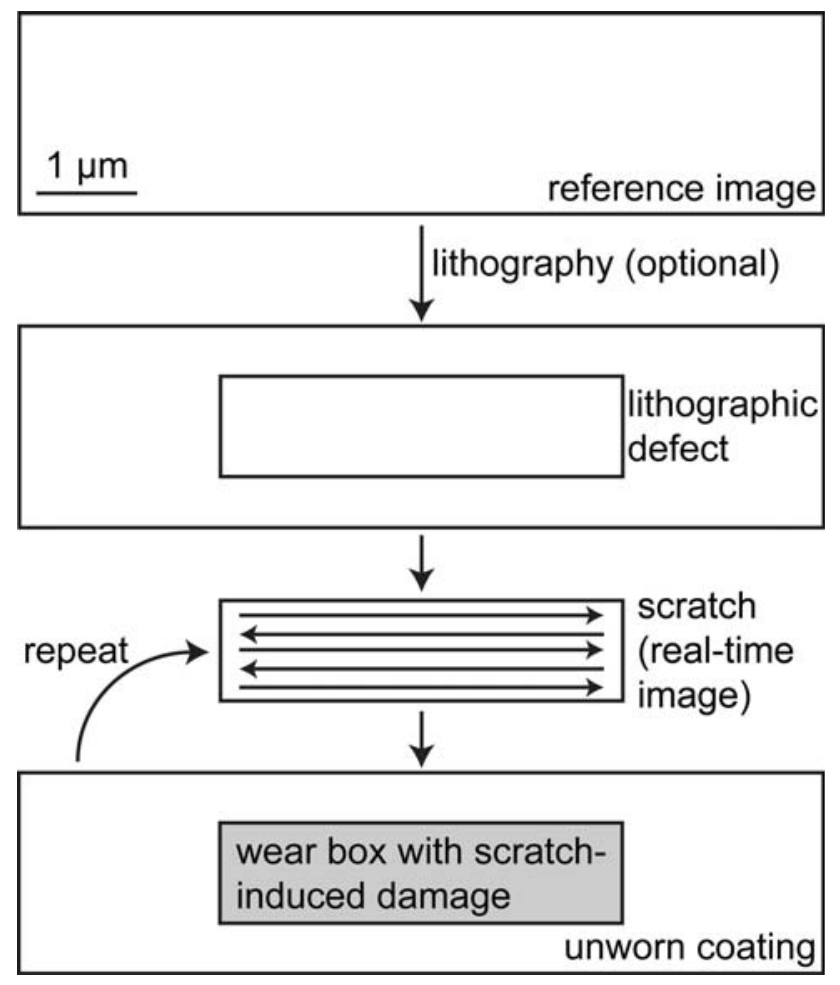

Fig. 1 The AFM nanoscratching process. Each coating was sequentially imaged (tapping mode), lithographed (contact mode), re-imaged (tapping), scratched (contact), and re-imaged (tapping). The last two steps were repeated until the coatings had been scratched up to 16 times

the wear box is unworn coating. The height of the unworn area was used as the zero point for quantification of coating wear. In addition, the hydrated coating thicknesses were calculated as the difference between the height of the unworn area and the surface of UHMWPE exposed by AFM nanoscratching.

\subsection{Relative crosslink density}

The crosslink density of the $40^{\circ} \mathrm{C}$ coatings relative to the $50^{\circ} \mathrm{C}$ coatings was determined by comparing the swelling behavior of the two sets of materials. Since coatings are constrained by the dimensions of the substrates to which they are bonded, they can swell in only one dimensionperpendicular to the substrate surface. Therefore, the swelling behavior was evaluated by measuring the coating thickness. The hydrated thicknesses of the $40^{\circ} \mathrm{C}$ and $50^{\circ} \mathrm{C}$ coatings were measured in PBS using AFM as described above. The relative dry thicknesses were measured by ATR-FTIR using the area under the ether peak at $\sim 1115 \mathrm{~cm}^{-1}$. The $40^{\circ} \mathrm{C}$ ATR-FTIR data were calibrated to the swollen thicknesses of the $40^{\circ} \mathrm{C}$ coatings as described previously [12], and the calibration curve was then used to predict the hydrated thicknesses of the $50^{\circ} \mathrm{C}$ coatings. The difference in crosslink density between the two sets of coatings was calculated from the true hydrated thickness of a particular $50^{\circ} \mathrm{C}$ coating $\left(t_{\text {hydrated }, 50}\right)$ and the hydrated thickness predicted by the calibration curve $\left(t_{\text {predicted,50 }}\right)$.

\section{Results and discussion}

\subsection{Coating characterization}

Two sets of coatings were investigated: one plasma-polymerized at $40^{\circ} \mathrm{C}$, and the other at $50^{\circ} \mathrm{C}$. XPS and contact angle goniometry both indicated that the two sets of coatings were chemically similar but not identical (see Table 1). Both exhibited PEG-like chemical structures with at least $75 \%$ ether content, comparable to the polymerized tetraglyme surfaces produced by Johnston et al. [13]. Both were also considerably more hydrophilic than uncoated UHMWPE, with a mean contact angle of $\sim 50^{\circ}$ versus $90^{\circ}$ for UHMWPE. However, the higher plasma deposition temperature $\left(50^{\circ} \mathrm{C}\right)$ produced surfaces with greater ether content, less hydrocarbon, and slightly less carbonyl than the lower-temperature coatings. The increase in hydrophilic ether bonding of the $50^{\circ} \mathrm{C}$ surfaces is a plausible explanation for the increased hydrophilicity of these coatings, indicated by their lower contact angle $\left(48.1^{\circ}\right.$, versus $53.5^{\circ}$ for the coatings produced at $40^{\circ} \mathrm{C}$ ).

Although the differences in chemical bonding and hydrophilicity between the $40^{\circ} \mathrm{C}$ and $50^{\circ} \mathrm{C}$ surfaces are

Table 1 Comparison of coatings produced at 40 and $50^{\circ} \mathrm{C}$

\begin{tabular}{llllll}
\hline $\begin{array}{l}\text { Deposition } \\
\text { temperature }\left({ }^{\circ} \mathrm{C}\right)\end{array}$ & \multicolumn{2}{l}{ XPS C 1s bonding } & & Contact angle $\left({ }^{\circ}\right)$ & Thickness range $(\mathrm{nm})$ \\
\cline { 2 - 5 } & $\% \mathrm{CH}_{x}$ & $\% \mathrm{C}-\mathrm{O}$ & $\% \mathrm{C}=\mathrm{O}$ & \\
\hline N/A (uncoated) & $95.7(1.6)$ & $4.0(1.4)$ & $0.4(0.8)$ & $90.3(1.1)$ & N/A \\
40 & $17.9(2.9)$ & $75.1(2.6)$ & $7.0(0.8)$ & $53.5(0.9)$ & $29-195$ \\
50 & $11.9(0.7)$ & $82.6(1.2)$ & $5.5(0.6)$ & $48.1(1.6)$ & $125-250+$ \\
\hline
\end{tabular}

The results displayed are the mean values for all coatings produced at each temperature $(n=4$ for each group for both XPS and contact angle measurements); the standard deviations are shown in parentheses. For each type of chemical bonding, the three groups are significantly different, as are their contact angles $(P<0.05$ in all cases $)$ 
statistically significant $(P<0.05)$, they are still relatively small. Overall, both sets of coatings were predominantly PEG-like and relatively hydrophilic, and they exhibited comparable root mean square (RMS) surface roughness, on the order of 20-30 nm-the same as untreated UHMWPE samples. The range of thicknesses of each set of coatings overlapped substantially, but the $40^{\circ} \mathrm{C}$ coatings were, as a group, thinner than the $50^{\circ} \mathrm{C}$ coatings (see Table 1) due to shorter plasma deposition times. However, despite their apparent similarity, the two sets of coatings behaved very differently when subjected to AFM nanoscratching.

\subsection{AFM nanoscratching: coatings produced at $50^{\circ} \mathrm{C}$}

The coatings produced at $50^{\circ} \mathrm{C}$ exhibited three microscale damage behaviors: roughening, thinning, and delamination (Figs. 2, 3, and 4, respectively). Roughening usually occurred early in the scratching process, typically after 1-2 scratches. It resulted in visible shallow texture development on the surface of the coating, along with a quantitative increase in RMS roughness in the worn region relative to the unworn coating (see Fig. 2). The effect of roughening can be seen clearly by comparing histograms of the surface topography of worn and unworn areas of the coating. As Fig. 2 shows, the worn region exhibits a much wider topographical distribution than the unworn region, but both are centered around zero. This indicates that roughening caused shallow peaks and valleys to form, but no material was actually lost from the coating surface. It is important to note that roughening is a surface-specific process: all coatings produced at $50^{\circ} \mathrm{C}$ were at least $125 \mathrm{~nm}$ thick, and roughening caused damage to the top $40 \mathrm{~nm}$ or less.

After a few scratches, the wear mode changed to thinning or delamination, which both resulted in large-scale coating removal, often down to the UHMWPE surface. During AFM nanoscratching, bare UHMWPE wore distinctively, forming peaks and troughs perpendicular to the wear direction with a period of $\sim 1 \mu \mathrm{m}$ that deepened with continued scratching [11]. Similar behavior has been observed for UHMWPE subjected to a variety of wear conditions, including pin-on-disk testing [14] and joint simulators $[15,16]$. The appearance of periodic peaks and troughs, shown in Fig. 4d, was therefore used to determine when the coatings had been worn away and the UHMWPE substrate uncovered.

Thinning involved gradual coating loss throughout the entire wear box over a series of scratches. During thinning, illustrated in Fig. 3, the wear box deepened with each successive scratch, but the bottom surface did not roughen substantially until the coating was entirely removed. At that point, the peaks and troughs characteristic of UHMWPE wear appeared. During each scratch, with 1$2 \mu \mathrm{N}$ of normal load applied, $6-35 \mathrm{~nm}$ of coating thickness were removed. In most cases, the wear rate of the coating decreased with successive scratching, likely because the overall system (the coating plus UHMWPE) stiffened as the distance to the stiffer UHMWPE substrate decreased.

Unlike thinning, which involved progressive coating wear over a series of scratches, delamination occurred

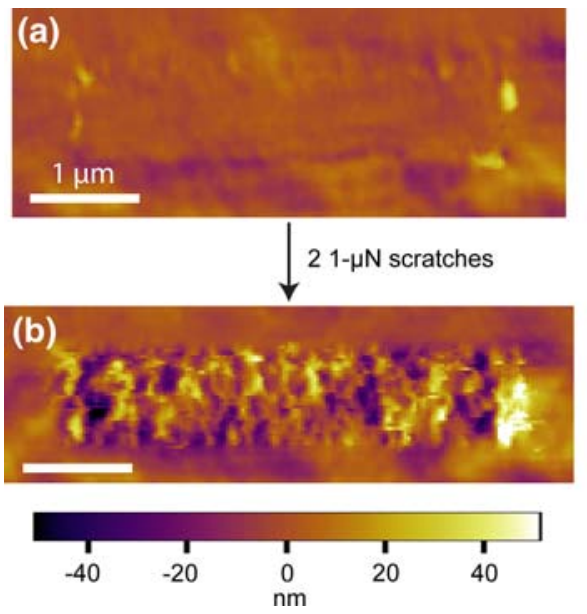

Fig. 2 An example of roughening of a $50^{\circ} \mathrm{C}$ coating. a An image of the surface after a lithographic pre-scratch, but prior to scratching of the entire wear box. b The same surface after two $1 \mu \mathrm{N}$ scratches within the wear box. Texture development is clearly visible throughout the worn region, as compared to both the image before scratching and the unworn region of the image post-scratching. $\mathbf{c}$ A histogram of the surface topography of the unworn area outside of the wear box shown in $\mathbf{b}$. Since this image was produced by subtracting an initial
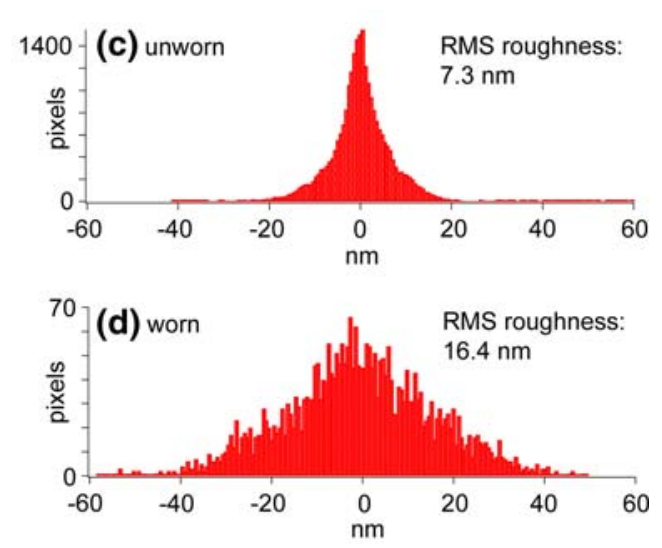

reference image from the post-scratching image, all features located outside the worn region are artifacts of image processing. But it is important to compare the RMS roughness of the worn region to that of the processed unworn region in order to ensure that all results in the worn region are real, rather than image processing artifacts. d A histogram of the worn area. The topography distribution widened considerably after scratching, and this is reflected in the increased RMS roughness of the worn region 


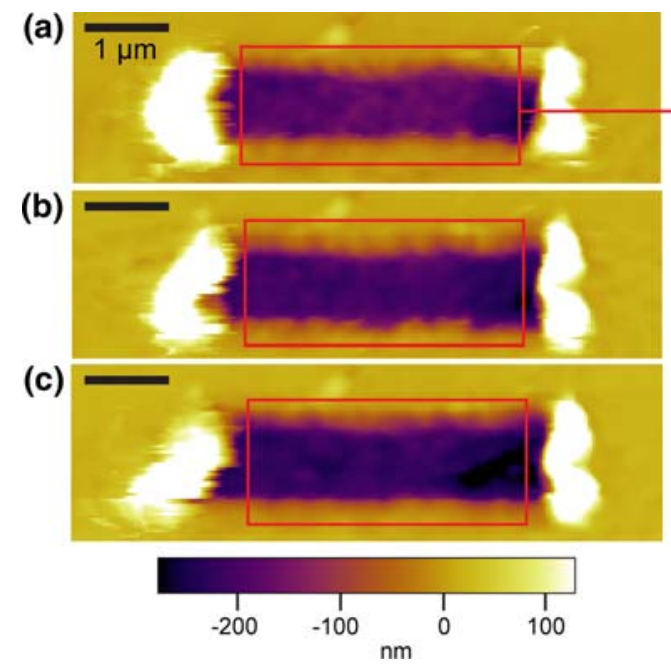

Fig. 3 An example of thinning of a $50^{\circ} \mathrm{C}$ coating. The data shown here are from the first six scratches, two at $2 \mu \mathrm{N}$ of normal load followed by four at $1 \mu \mathrm{N}$. The images on the left show the surface after a two, b four, and $\mathbf{c}$ six scratches. The histograms on the right, which are derived from the areas within the red boxes in parts a-c, exhibit peaks from the worn region and unworn regions of the coating

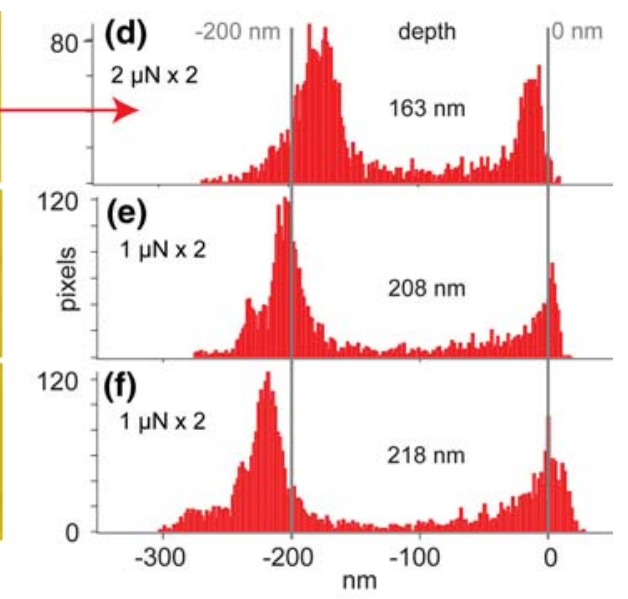

after $\mathbf{d}$ two, e four, and $\mathbf{f}$ six scratches. As scratching continued, the difference between the worn and unworn peaks - the depth of the wear box-increased, indicating that the material was progressively lost from the worn region; however, the topographical distribution within the worn region did not widen substantially, indicating that the bottom of the wear box was not progressively roughening
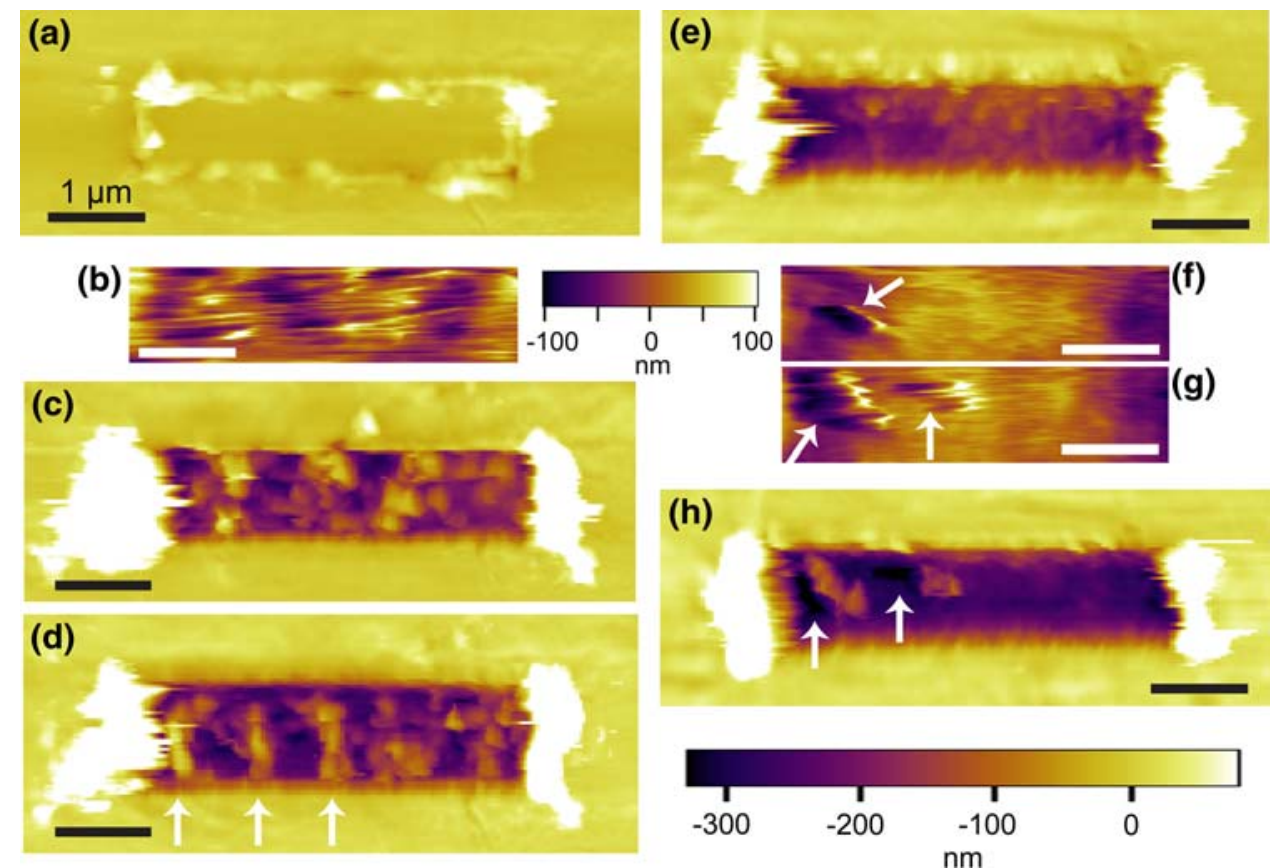

Fig. 4 Two examples of delamination of $50^{\circ} \mathrm{C}$ coatings. The left side shows a scratch sequence that starts with $\mathbf{a}$ an unworn coating with a lithographic pre-scratch, followed by $\mathbf{b}$ a real-time image taken during the first $2 \mu \mathrm{N}$ scratch, then $\mathbf{c}$ the surface after the scratch, with considerable damage and coating pile-up to the sides of the wear box (the white mounds). d Two additional $1 \mu \mathrm{N}$ scratches partially uncovered the UHMWPE surface, as evidenced by the periodic peaks and troughs indicated by the arrows on the left side of the wear box. The right side of this figure shows a different scratch sequence that

starts with e coating that had previously worn by thinning, followed by $\mathbf{f}$ and $\mathbf{g}$ real-time images taken during two consecutive $1.5 \mu \mathrm{N}$ scratches, then $\mathbf{h}$ the surface after those two scratches. During the scratch shown in (f), a hole started to form on the left side of the wear box, indicated with an arrow; the hole enlarged during the scratch shown in ( $\mathbf{g})$, and a second hole started to form closer to the middle, also indicated with an arrow. These delamination defects are clearly visible in (h), which shows that the right side of the wear box continued to thin while the left delaminated 


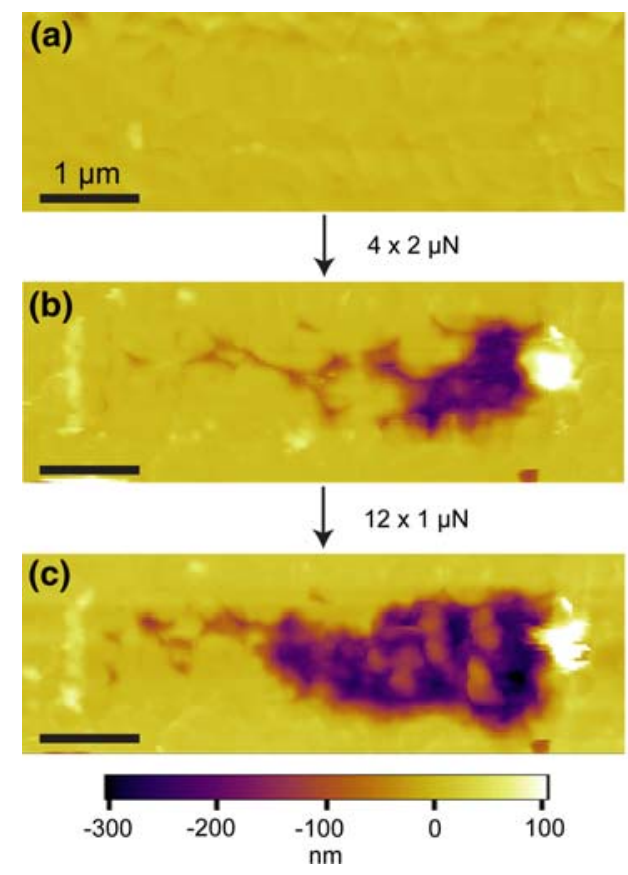

Fig. 5 An example of $40^{\circ} \mathrm{C}$ coating wear. The left side shows scratch sequence that starts with a an unworn coating with a lithographic prescratch (barely visible), followed by b an image after four $2 \mu \mathrm{N}$ scratches and $\mathbf{c}$ an image after an additional twelve $1 \mu \mathrm{N}$ scratches. Delamination occurred on the right side of the wear box within the first four scratches, and the damage had progressed to the middle by the end of the 16-scratch sequence. However, some parts of the left side of the wear box remained intact. $\mathbf{d}$ The same image as in (c), with

during single scratches that caused large amounts of material loss. In the most extreme instances, the full thickness of the coating (tens to hundreds of nanometers) was removed from the entire $4 \mu \mathrm{m}^{2}$ wear box. In other cases, delamination removed only part of the coating (either partial area or partial thickness). Delamination often accompanied or followed other wear modes. For example, some coatings roughened and then delaminated, while others thinned and then delaminated, or exhibited both behaviors in a single scratch. Figure 4 shows two different delamination events: removal of the almost the entire coating thickness across the whole wear box, leaving behind some fragments of coating that caused the rough appearance of the bottom of the wear box; and delamination combined with thinning, such that most of the coating wore by thinning, while two holes formed by delamination.

\subsection{AFM nanoscratching: coatings produced at $40^{\circ} \mathrm{C}$}

In contrast to the coatings produced at $50^{\circ} \mathrm{C}$, the coatings produced at $40^{\circ} \mathrm{C}$ did not exhibit roughening or thinning. These coatings either delaminated or did not wear at all. Figure 5 illustrates a typical scratch sequence, which resulted in partial delamination of the wear box after 16 scratches. As the histograms in Fig. 5e, f confirm, the area
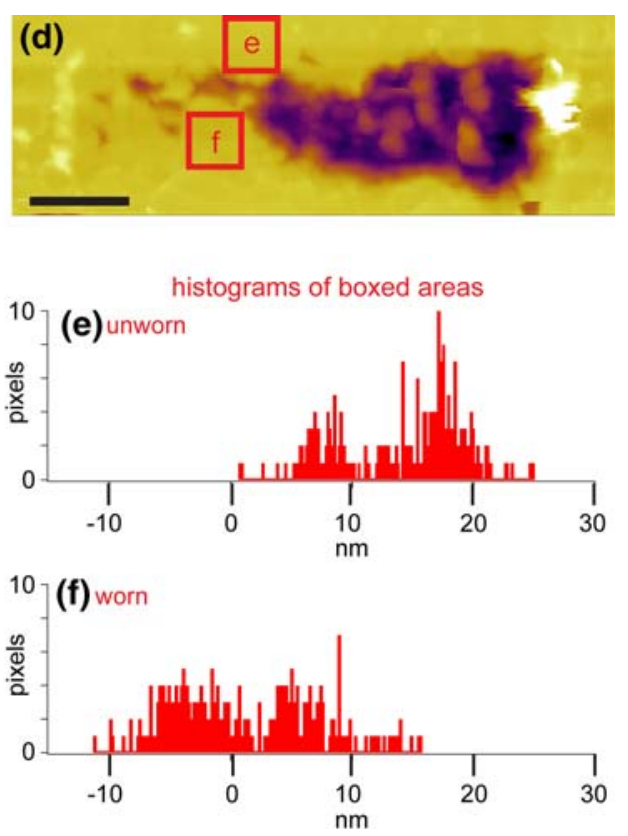

two boxes added to show the locations of the histograms shown in $\mathbf{e}$ an unworn region of coating and $\mathbf{f}$ a worn but undamaged area. The unworn region is actually rougher than the worn coating (14.9 nm vs. $6.1 \mathrm{~nm}$ RMS roughness); however, the topographical distribution of the worn area is downshifted by $\sim 15 \mathrm{~nm}$, indicating a loss of approximately $1 \mathrm{~nm}$ of coating thickness per scratch. This rate is considerably lower than any observed for the $50^{\circ} \mathrm{C}$ coatings

that did not delaminate shows no signs of roughening and very minimal material loss (less than $1 \mathrm{~nm}$ of coating thickness per scratch), a result that was never observed in the $50^{\circ} \mathrm{C}$ coatings. Regardless of whether or not the surface had been pre-scratched, all coatings produced at $50^{\circ} \mathrm{C}$ exhibited visible damage within two scratches.

The increased wear resistance of the $40^{\circ} \mathrm{C}$ coatings relative to the $50^{\circ} \mathrm{C}$ coatings was unexpected, and several explanations were considered, including differences in coating chemistry, hydrophilicity, and thickness, all shown in Table 1. However, none of these provided an adequate reason for the dramatic difference in behavior, and some of the results were counter-intuitive. While the $50^{\circ} \mathrm{C}$ coatings did have somewhat more ether and less hydrocarbon and carbonyl content than the $40^{\circ} \mathrm{C}$ coatings, the differences $(7.5 \%, 6.0 \%$, and $1.5 \%$, respectively) do not seem large enough to substantially alter the mechanical properties of the surface. It is interesting to note that the more PEG-like $50^{\circ} \mathrm{C}$ coatings, initially expected to be the superior surface, were less wear-resistant. Similarly, the more PEG-like $50^{\circ} \mathrm{C}$ coatings were slightly (but statistically significantly) more hydrophilic, which should have lead to increased lubricity and decreased wear-but the opposite behavior was observed. The more hydrophilic coatings were less wear-resistant. 
Finally, one might have expected the thicker set of coatings to be more wear-resistant, but they were not. Among each set of coatings produced at the same temperature, the thicker coatings often required more scratches, higher normal forces, or pre-scratching in order to fully remove the PEG-like layer. However, the wear modes exhibited by the coatings were independent of coating thickness. Even the thinnest $40^{\circ} \mathrm{C}$ coatings, just $29 \mathrm{~nm}$ thick, exhibited only delamination wear, while the thickest $50^{\circ} \mathrm{C}$ coatings, greater than $250 \mathrm{~nm}$ thick, both thinned and delaminated.

\subsection{Assessment of relative crosslink density}

To explain the difference in wear behavior between the two sets of coatings, we hypothesized that the more wearresistant $40^{\circ} \mathrm{C}$ coatings might be more crosslinked. Increased crosslinking is known to improve the wear resistance of polymers, including UHMWPE for total joint replacements [4, 5] as well as hydrogels such as poly(2hydroxyethyl methacrylate) (PHEMA) proposed for use as artificial cartilage [17, 18].

The crosslink density of the PEG-like coatings was evaluated by measuring the relative swelling of the 40 and $50^{\circ} \mathrm{C}$ coatings in PBS. According to the classic polymer swelling theory developed by Flory [19], for a polymer swollen to equilibrium in a pure solvent, the swelling ratio $q$ is related to the molecular weight between crosslinks $M_{c}$ by

$-\left[\ln \left(1-\frac{1}{q}\right)+\frac{1}{q}+\frac{\chi_{1}}{q^{2}}\right]=\frac{V_{1}}{v M_{c}}\left(1-\frac{2 M_{c}}{M}\right)\left(\frac{1}{q^{1 / 3}}-\frac{1}{2 q}\right)$.

$\chi_{1}$ is the polymer-solvent interaction parameter, $V_{1}$ is the molecular volume of the solvent, $v$ is the specific volume of the polymer, and $M$ is the primary molecular weight. For lightly crosslinked networks, this equation can be simplified to

$q^{5 / 3} \approx \frac{v M_{c}}{V_{1}}\left(\frac{1 / 2-\chi_{1}}{1-\left(2 M_{c} / M\right)}\right)$

The crosslink density $X$ of a hydrogel is inversely proportional to the molecular weight between crosslinks. Equation 2 can be further simplified to yield an approximate relationship between the crosslink density and the swelling ratio [20]:

$X \propto \frac{1}{q^{5 / 3}}$.

The swelling ratio is the ratio of the hydrated hydrogel volume to the dry volume. Due to the constraints of surface attachments, the cross-sectional area $A_{c}$ of a coating covalently bonded to a surface cannot change, so these coatings swell in only one direction, perpendicular to the surface. Therefore, the swelling ratio depends only on the change in film thickness, $t$, upon hydration:

$q=\frac{A_{c} t_{\text {hydrated }}}{A_{c} t_{\text {dry }}}=\frac{t_{\text {hydrated }}}{t_{\text {dry }}}$.

In this study, the hydrated coating thicknesses were measured by AFM after nanoscratching fully removed the PEG-like layer. Previous experiments established a linear relationship between the hydrated thicknesses of the $40^{\circ} \mathrm{C}$ coatings measured by AFM and the area under the ether peak $\left(a_{\text {ether }}\right)$ of ATR-FTIR spectra of the coatings taken dry (in ambient conditions) [12]:

$t_{\text {hydrated }, 40}=11.1 a_{\text {ether }}$.

Initially, we assumed that the same relationship could be applied to the coatings produced at $50^{\circ} \mathrm{C}$ to predict their hydrated thicknesses $\left(t_{\text {predicted }}\right)$. However, as Table 2 shows, Eq. 5 consistently underestimated the hydrated thickness of the coatings, suggesting that the two sets of coatings have different swelling ratios.

To examine the difference between the swelling ratios, consider the scenario of two coatings, one produced at $40^{\circ} \mathrm{C}$ and one produced at $50^{\circ} \mathrm{C}$, with identical dry ether peak areas. Since ATR-FTIR simply measures a number of covalent bonds per unit volume, dry coatings with equal ether peak areas should have the same dry thickness, regardless of their production temperature or swelling behavior. Therefore, the dry thickness of both sets of coatings should be

$t_{d r y}=k a_{\text {ether }}$,

where $k$ is an unknown calibration constant that is equivalent for both coatings. Of course, the hydrated

Table 2 Relative degree of crosslinking for three different $50^{\circ} \mathrm{C}$ coatings

\begin{tabular}{llllr}
\hline Sample & $\begin{array}{l}\text { Ether peak } \\
\text { area } a_{\text {ether }}\end{array}$ & $\begin{array}{l}\text { Predicted thickness }(\mathrm{nm}) \\
t_{\text {predicted }}=11.1 a_{\text {ether }}\end{array}$ & $\begin{array}{l}\text { True hydrated } \\
\text { thickness }(\mathrm{nm})\end{array}$ & $\begin{array}{c}X_{40} \\
X_{50}\end{array}\left(^{\frac{t_{\text {hydrated }}, 50}{t_{\text {predicted }}}}\right)^{5 / 3}$ \\
\hline 1 & $9.8(0.8)$ & $109(9)$ & $125(19)$ & 1.26 \\
2 & $16.0(0.4)$ & $178(5)$ & $210(14)$ & 1.32 \\
3 & $19.5(1.4)$ & $216(15)$ & $>250$ & $>1.28$ \\
\hline
\end{tabular}

Standard deviations are shown in parentheses. For the ether peak area measurements, $n=4$. For the true hydrated thicknesses, $n=3$. The true hydrated thickness of Sample 3 was difficult to measure by AFM because the coating wore very unevenly. It is possible that the lithographic prescratch did not fully penetrate the coating, so the coating did not tear away cleanly from the UHMWPE substrate 
thickness of the two coatings should be different. The hydrated thickness of the $40^{\circ} \mathrm{C}$ coating can be predicted by Eq. 5, while the hydrated thickness of the $50^{\circ} \mathrm{C}$ coating must be measured by AFM. Using Eqs. 4-6, the ratio of swelling ratios of these two coatings can be calculated as

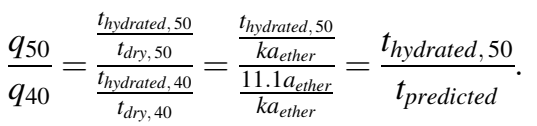

According to the relationship between crosslink density and swelling shown in Eq. 3,

$\frac{X_{40}}{X_{50}}=\left(\frac{q_{50}}{q_{40}}\right)^{5 / 3}=\left(\frac{t_{\text {hydrated }, 50}}{t_{\text {predicted }}}\right)^{5 / 3}$.

Therefore, the ratio of the hydrated $50^{\circ} \mathrm{C}$ coating thickness to the thickness predicted by Eq. 5 for the same $a_{\text {ether }}$ indicates the relative degree of crosslinking of the $40^{\circ} \mathrm{C}$ versus $50^{\circ} \mathrm{C}$ coatings. It is expected that more crosslinking should improve wear resistance; therefore, the $40^{\circ} \mathrm{C}$ coatings should be more crosslinked than the $50^{\circ} \mathrm{C}$ coatings. This agrees well with the results, which show that the $50^{\circ} \mathrm{C}$ coatings consistently swelled more than predicted for $40^{\circ} \mathrm{C}$ coatings with the same ether content. As calculated from Eq. 8, the $40^{\circ} \mathrm{C}$ coatings have $26-32 \%$ higher crosslink density than the $50^{\circ} \mathrm{C}$ coatings (see Table 2).

Although the difference in crosslink density between the $40^{\circ} \mathrm{C}$ and $50^{\circ} \mathrm{C}$ coatings likely explains the difference in wear behavior between them, it is important to consider the assumptions underlying the relative crosslink density calculations. Equation 1 is valid only for networks swollen to equilibrium in good solvents [19]. Since the PEG-like coatings were fully immersed in PBS for at least $30 \mathrm{~min}$ during these experiments, the coatings should have been swollen to equilibrium, and water is a good solvent for PEG. Therefore the assumptions for Eq. 1 are valid.

Equation 2 is derived from the assumption that the polymer network is very lightly crosslinked, such that $q \geq 10$ [19], and Eq. 3 further assumes a nearly-perfect network with few chain ends $(M \rightarrow \infty)$. For the PEG-like coatings, neither the actual degree of crosslinking nor the number of chain ends is known. However, if $M$ is high enough to neglect the $2 M_{c} / M$ term in Eq. 2, the effect of varying $q$ can be evaluated. For $q=1.01$ (a highly-crosslinked network swollen only 1\%), Eq. 2 overestimates the molecular weight between crosslinks by $100 \%$ compared to Eq. 1. However, this effect drops significantly as $q$ increases: for $q=2, M_{c}$ is $\sim 50 \%$ too high, and for $q=5$, $M_{c}$ is only $\sim 20 \%$ too high. In addition, if two networks have similar $q$ values, their molecular weights between crosslinks will be overestimated by a similar amount. Recalling that the crosslink density $\mathrm{X}$ is the inverse of $M_{c}$, the crosslink densities will be underestimated, but to a similar extent.
Since Eq. 8 takes the ratio of the crosslink densities, the underestimation caused by assuming an overly high $q$ value should be eliminated, as long as the swelling ratios of the $40^{\circ} \mathrm{C}$ and $50^{\circ} \mathrm{C}$ coatings are relatively similar. That is, if both coatings have a swelling ratios of $\sim 5, X$ should be underestimated by $\sim 20 \%$ for both coatings, and $0.8 X_{40} /$ $0.8 X_{50}$ equals $X_{40} / X_{50}$. However, the crosslink density of the $40^{\circ} \mathrm{C}$ coatings, which have a lower swelling ratio, should be underestimated more than that of the $50^{\circ} \mathrm{C}$ coatings. Therefore, the results of this calculation should slightly underestimate the difference in crosslink density between the two coatings- the opposite of the effect being demonstrated. Although this analysis indicates that the ratio of the crosslink densities of the 40 and $50^{\circ} \mathrm{C}$ is an approximation, the calculation is still valid and may in fact underestimate the difference in crosslinking.

The difference in wear resistance between the 40 and $50^{\circ} \mathrm{C}$ coatings suggests that further investigation into the effect of crosslinking is necessary. It is likely that three regimes of wear behavior exist: moderate wear resistance, similar to that exhibited by the $50^{\circ} \mathrm{C}$ coatings, at low crosslink density; improved resistance, similar to the behavior of the $40^{\circ} \mathrm{C}$ coatings, at intermediate density; and decreasing resistance at high crosslink density, as the coating becomes embrittled and also unable to absorb as much water.

The role of fluid lubrication also remains open. For the PEG-like coatings examined here, it is interesting to note that increased crosslinking played a more significant role in determining wear behavior than increased hydrophilicity. This may have been because the difference in hydrophilicity between the 40 and $50^{\circ} \mathrm{C}$ coatings was small; however, the observation merits further research. Once the most promising combination of crosslink density and surface hydrophilicity has been identified, larger-scale wear testing, including pin-on-disk and joint simulator studies, will be necessary to determine whether the coatings can significantly decrease the wear rate of UHMWPE under clinically-relevant conditions.

\section{Conclusions}

Two sets of PEG-like coatings were produced at different plasma deposition temperatures, 40 and $50^{\circ} \mathrm{C}$. They exhibited similar but statistically significantly different coating chemistry and hydrophilicity, with the coatings produced at $50^{\circ} \mathrm{C}$ having a higher ether content and higher hydrophilicity. Although these qualities initially suggested that the $50^{\circ} \mathrm{C}$ coatings would be more wear resistant, AFM nanoscratching experiments indicated that they consistently showed evidence of damage after 1-2 scratches, and they exhibited three modes of wear behavior, roughening, 
thinning, and delamination. In contrast, the $40^{\circ} \mathrm{C}$ coatings were much more wear-resistant, with parts of some coatings remaining intact after up to 16 scratches. The $40^{\circ} \mathrm{C}$ coatings also did not roughen, and they thinned negligibly. Swelling data indicate that the difference is attributable to a difference in the degree of crosslinking of the two sets of coatings, as the more wear-resistant $40^{\circ} \mathrm{C}$ coatings were approximately $30 \%$ more crosslinked than the $50^{\circ} \mathrm{C}$ coatings. This finding has design implications for all hydrogel coatings with wear-related applications, and it is particularly relevant for total hip replacements and artificial cartilage, since crosslinking had a greater effect on wear behavior than hydrophilicity in this study.

Acknowledgements This work was supported by the NSF (grant \#CMS 0505272 and a Graduate Research Fellowship), a Sigma Xi Grant-in-Aid of Research, a UCSF Graduate Student Research Award, and the American Association of University Women. AFM work at the Molecular Foundry was supported by the Director, Office of Science, Office of Basic Energy Sciences, Division of Materials Science and Engineering, of the U.S. Department of Energy under Contract \#DE-AC02-05CH11231. XPS was performed at the University of Washington NESAC/BIO facility, supported by NIH grant \#EB-002027. In addition, the authors would like to acknowledge Kyriakos Komvopoulos for his tribology expertise, Stephanie Uhlich and Amy Walters for their contributions to the contact angle experiments, and Stephen Kaplan and 4th State Inc. for assistance with and use of their plasma equipment.

Open Access This article is distributed under the terms of the Creative Commons Attribution Noncommercial License which permits any noncommercial use, distribution, and reproduction in any medium, provided the original author(s) and source are credited.

\section{References}

1. Wang ML, Sharkey PF, Tuan RS. Particle bioreactivity and wearmediated osteolysis. J Arthroplasty. 2004;19:1028-38.

2. Ingham E, Fisher J. Biological reactions to wear debris in total joint replacement. Proc Inst Mech Eng H. 2000;214:21-37.

3. Archibeck MJ, Jacobs JJ, Roebuck KA, Glant TT. The basic science of periprosthetic osteolysis. J Bone Joint Surg Am. 2000;82A:1478-89.

4. Kurtz SM, Muratoglu OK, Evans M, Edidin AA. Advances in the processing, sterilization, and crosslinking of ultra-high molecular weight polyethylene for total joint arthroplasty. Biomaterials. 1999;20:1659-88.

5. Muratoglu OK, Bragdon CR, O'Connor DO, et al. Unified wear model for highly crosslinked ultra-high molecular weight polyethylenes. Biomaterials. 1999;20:1463-70.

6. Baker DA, Bellare A, Pruitt L. The effects of degree of crosslinking on the fatigue crack initiation and propagation resistance of orthopedic-grade polyethylene. J Biomed Mater Res A. 2003; 66A:146-54.

7. Collier JP, Currier BH, Kennedy FE, et al. Comparison of crosslinked polyethylene materials for orthopedic applications. Clin Orthop Relat Res. 2003;414:289-304.

8. Moro T, Takatori Y, Ishihara K, et al. Surface grafting of artificial joints with a biocompatible polymer for preventing periprosthetic osteolysis. Nat Mater. 2004;3:829-36.

9. Pavoor PV, Gearing BP, Muratoglu O, Cohen RE, Bellare A. Wear reduction of orthopaedic bearing surfaces using polyelectrolyte multilayer nanocoatings. Biomaterials. 2006;27:1527-33.

10. Zhang M, Pare P, King R, James SP. A novel ultra high molecular weight polyethylene-hyaluronan microcomposite for use in total joint replacements. II. Mechanical and tribological property evaluation. J Biomed Mater Res A. 2007;82A:18-26.

11. Kane SR, Ashby PD, Pruitt LA. Characterization and tribology of PEG-like coatings on UHMWPE for total hip replacements. J Biomed Mater Res A. 2009. doi:10.1002/jbm.a.32484.

12. Kane SR, Ashby PD, Pruitt LA. ATR-FTIR as a thickness measurement technique for hydrated polymer-on-polymer coatings. J Biomed Mater Res B. 2009;91(2):613-20.

13. Johnston EE, Bryers JD, Ratner BD. Plasma deposition and surface characterization of oligoglyme, dioxane, and crown ether nonfouling films. Langmuir. 2005;21:870-81.

14. Zhou J, Chakravartula A, Pruitt L, Komvopoulos K. Tribological and nanomechanical properties of unmodifiedand crosslinked ultra-high molecular weight polyethylene for total joint replacements. J Tribol-Trans ASME. 2004;126:386-94.

15. McKellop HA, Campbell P, Park SH, et al. The origin of submicron polyethylene wear debris in total hip arthroplasty. Clin Orthop Relat Res. 1995;311:3-20.

16. Wang A, Stark C, Dumbleton JH (1996) Mechanistic and morphological origins of ultra-high molecular weight polyethylene wear debris in total joint replacement prostheses [comment]. Proc Inst Mech Eng H. 210:141-55.

17. Freeman ME, Furey MJ, Love BJ, Hampton JM. Friction, wear, and lubrication of hydrogels as synthetic articular cartilage. Wear. 2000;241:129-35.

18. Bavaresco VP, Zavaglia CAC, Reis MC, Gomes JR. Study on the tribological properties of pHEMA hydrogels for use in artificial articular cartilage. Wear. 2008;265:269-77.

19. Flory PJ. Principles of polymer chemistry. London: Cornell University Press; 1953.

20. Flory PJ, Rehner J. Statistical mechanics of cross-linked polymer networks. II. Swelling. J. Chem. Phys. 1943;11:521-6. 